\title{
ZIWES, Franz-Josef, Studien zur Geschichte der Juden im mittleren Rheingebiet während des hohen und späten Mittelalters
}

Joseph Morsel

\section{OpenEdition}

Journals

Édition électronique

URL : http://journals.openedition.org/ifha/1550

DOI : 10.4000/ifha. 1550

ISSN : 2198-8943

Éditeur

IFRA - Institut franco-allemand (sciences historiques et sociales)

Référence électronique

Joseph Morsel, «ZIWES, Franz-Josef, Studien zur Geschichte der Juden im mittleren Rheingebiet während des hohen und späten Mittelalters », Revue de l'IFHA [En ligne], Date de recension, mis en ligne le 01 janvier 1996, consulté le 22 septembre 2020. URL : http://journals.openedition.org/ifha/1550 ; DOI : https://doi.org/10.4000/ifha.1550

Ce document a été généré automatiquement le 22 septembre 2020

(CIFHA 


\title{
ZIWES, Franz-Josef, Studien zur Geschichte der Juden im mittleren Rheingebiet während des hohen und späten Mittelalters
}

\author{
Joseph Morsel
}

L'histoire des Juifs en Allemagne n'est pas un terrain facile. Outre le poids du passé récent, qui interdit toute appréhension avec détachement de ce pan de l'histoire médiévale allemande et, au-delà, européenne, se posent également un certain nombre de problèmes méthodologiques et techniques, comme le fait que l'on a plus d'informations sur les Juifs fournies par les autres que par les Juifs eux-mêmes, que beaucoup de leurs sources sont en hébreu, que la succession des phases d'intégration et d'exclusion accompagnée d'expulsions ou de pogroms a provoqué la perte de beaucoup de matériaux historiques, que beaucoup d'études publiées souffrent d'un penchant apologétique ou inversement hyper-critique, etc. Or, l'histoire, notamment médiévale, des Juifs apparait de plus en plus incontournable, non seulement dans le cadre historiographique actuel qui accorde une attention soutenue à tous les groupes "marginaux« par rapport à l'ordre dominant (chrétien, masculin, aristocratique, etc.), mais aussi parce que l'on subodore que le judaïsme a joué un rôle beaucoup plus important qu'il n'y paraît (ou qu'on ne veut le reconnaître) dans la configuration du Moyen Age chrétien. Par ailleurs, les travaux de fond menés dans le cadre de l'entreprise Germania Judaica depuis 1903 avaient certes livré en 1934 un premier inventaire des implantations juives dans l'Empire, mais il n'allait que jusqu'en 1238 - et les années suivantes n'ont guère été propices à son utilisation. Ce n'est qu'à partir des années 60 que l'entreprise a repris - mais à Jérusalem - avec la réédition du premier volume et la publication du deuxième volume (jusqu'en 1350), ainsi qu'une grande exposition sur la »Germania Judaica« à Cologne (1963); le troisième volume (en cours de parution) permet(tra) de suivre les implantations jusqu'en 1519. La reprise des travaux allemands sur les Juifs au Moyen Age date de la fin des années 60 et surtout du début des années 70, avec une nette multiplication des publications dans les années 80 - et la 
fondation en 1987 de la Gesellschaft zur Erforschung der Geschichte der Juden, »Société pour l'étude de l'histoire des Juifs« (président actuel: A. HAVERKAMP) et en 1988 du Jüdisches Museum de Francfort/Main. Les quatre ouvrages présentés sont sur la crête de cette vague, en dépit de leur date de publication.

2 Le premier volume de la collection du Musée Juif de Francfort est consacré au grand pogrom qui a annihilé en mai 1241 la première communauté juive de Francfort. La date à laquelle les trois contributions qui composent ce petit volume ont été prononcées, le 10 novembre (le lendemain de la commémoration du 9 novembre 1938) 1991 (750 ans après le pogrom de Francfort) établit ainsi un lien symbolique entre la première et la dernière des persécutions antisémites organisées à Francfort. Une première contribution envisage l'arrière-plan du pogrom, marqué notamment par des craintes eschatologiques liées au péril mongol et au conflit pape/empereur (avec l'existence probable d'un fort parti anti-impérial à Francfort, alors que les Juifs de l'Empire sont depuis 1236 »serfs de la chambre« de l'Empereur). Une autre contribution ajoute à cela la très forte pression cléricale exercée dans les années 1230 contre le judaïsme (p. ex. interdiction du Talmud en 1239), notamment à l'aide des Dominicains alors en cours d'installation à Francfort, et examine le détail des informations livrées à l'époque sur ce pogrom (sources latines), tandis que la troisième contribution examine les sources hébraïques, soulignant notamment la différence des approches par rapport aux sources latines.

3 La communauté de Francfort fait partie de celles étudiées par F.-J.Z. dans sa dissertation doctorale (dirigée par A. Haverkamp et soutenue en 1992). Son ouvrage se penche en effet sur les Juifs du Rhin moyen (environ de Coblence à Spire) et sur ses affluents (notamment la Moselle jusqu'à Cochem, le Main jusqu'à Aschaffenbourg et le Neckar jusqu'à Heilbronn. L'étude procède en trois temps: tout d'abord un examen de l'implantation spatiale, de sa densification (avec un maximum atteint au début du XIVe s., brisé à jamais dans les années 1348/49) et de ses modifications de 1084 à 1520, appuyé sur un jeu de cartes conséquent. Puis l'étude détaillée des formes de l'implantation juive: les points forts du réseau (mesurés à l'aune de la notion de »lieux centraux « courante dans la recherche sur les réseaux urbains et les rapports villes/ campagnes, ainsi qu'à l'aide de certains indicateurs comme la présence d'une organisation collective institutionnalisée, d'un cimetière, d'une synagogue, de bains, etc.), qui apparaissent être Mayence, Worms et Spire, les rapports des implantations juives avec les rois, princes, nobles et villes (notamment du point de vue de la fondation ou refondation des communautés, de leur protection et des intérêts financiers liés à tout ceci) et la mobilité géographique des Juifs (mobilité courante déterminée par des raisons religieuses, économiques ou politiques; mobilité exceptionnelle, marquée notamment par un glissement vers les campagnes et vers l'Est, déterminée par les grandes expulsions, comme celle ordonnée par Philippe le Bel, ou la fuite devant les persécutions). La troisième partie envisage enfin les persécutions et expulsions ellesmêmes. L'ouvrage s'achève par de volumineuses annexes qui présentent une intéressante partie du matériau traité.

$4 \quad$ F.-J.Z. est également co-directeur (avec A.H.) de la publication des actes des conférences prononcées sur le thème du judaïsme médiéval lors du Congrès des Historiens Allemands à Bamberg, en 1988. Le volume groupe quatre textes. Deux se préoccupent de la géographie historique du judaïsme médiéval: l'un envisage un thème détaillé par F.-J.Z. dans sa thèse: les migrations juives à l'ouest de l'Empire, notamment à la suite 
des expulsions françaises. Un autre envisage de manière plus large l'évolution de la structure de l'implantation juive en Europe centrale (y compris l'Empire) du XIVe au XVIe s., marquée par un lent glissement vers l'Est européen, vers les campagnes et vers des micro-communautés. Les deux autres textes examinent des formes de persécution fondées sur l'assimilation des Juifs et des hérétiques. C'est notamment le cas avec la condamnation du Talmud comme hérétique et son autodafé à Paris en 1242 (un fait autour duquel s'est cristallisée en 1871 l'appellation injurieuse de »Talmudjude«), à l'instigation de la hiérarchie ecclésiastique. Mais c'est aussi le cas lors d'assimilations, échappant au contrôle de l'Église, des Juifs et des Hussites, qui se traduisent notamment par des massacres de Juifs sur la route des croisades contre les Hussites (dont on trouve entre autres la trace dans une chronique juive du milieu du XVe s., dont la traduction est donnée en annexe).

L'ouvrage de R.R. (publication de sa dissertation doctorale soutenue en 1990). commence par brosser la situation historiographique et rappeler que la vie des communautés juives est déterminée par la combinaison de leurs positions de marginalité idéologique (religieuse) et d'intégration dans les cadres seigneuriaux (statut de dépendance), deux données qui déterminent en sens inverse l'ampleur et la fréquence des persécutions, R.R. examine le détail des implantations juives, territoire par territoire de la Basse-Saxe (Goslar, évêché de Hildesheim, trois principautés welfes) et agglomération après agglomération (pour finir par les mentions isolées). Elle examine ensuite les dimensions juridiques dans lesquelles vivent les communautés et notamment entrent en rapport avec les chrétiens, puis la "politique juive« des autorités en question, caractérisée notamment par la protection des Juifs contre rémunération et un faible soutien, voire une condamnation des persécutions et expulsions qui menaçaient une source importante de revenus. Viennent ensuite une étude de la situation économique des Juifs (qui sans être jamais vraiment fortunés occupent une position importante dans la vie économique de la région en raison de leurs activités de crédit »à la petite semaine«, mais une activité dont ils perdent leur quasi-monopole au XVIe s. au profit des institutions urbaines de crédit) et l'examen de leur situation sociale au sens large (allant de leur fréquentation au niveau privé et financier à leur rejet en termes globaux, ainsi qu'aux mutations provoquées par une Réforme rejetant l'anti-judaïsme papiste, sans que l'on puisse parler d'une adhésion populaire complète à cette nouvelle perception). R.R. étudie ensuite l'organisation interne (sociale, religieuse, administrative et économique) des communautés juives, ainsi que les échanges qui peuvent se tisser entre elles par la mobilité des personnes. Une dernière partie revient (pourquoi ici?) sur les représentations antisémites collectives (politiques) et privées. L'ampleur et l'intérêt du travail et des résultats sont souvent desservis par un plan peu adéquat, trop souvent »à tiroirs« et qui tend donc à niveler la valeur des observations. 